\section{Medical Students' Attitudes Regarding the Impact of a Therapy Dog Program on Anx- iety Levels: A Pilot Study}

\author{
Sara Brisson ${ }^{1 *}$, Samuel Purkey ${ }^{2}$ and Michael Brisson ${ }^{2}$ \\ ${ }^{1}$ Graduate Institute of Professional Psychology, University of Hartford, \\ West Hartford, Connecticut, USA
}

${ }^{2}$ Edward Via College of Osteopathic Medicine, Auburn, Alabama, USA

\begin{abstract}
\section{Background}

Animal-Assisted Therapy (AAT) has become common in both medical and educational settings. Evidence supports AAT as a beneficial therapeutic alternative for individuals suffering from physical disabilities and psychological disorders. In the medical schools, the use of therapy dogs has been markedly increasing on campuses due to a variety of documented mental health concerns. However, no research has examined the impact of a therapy dog program on medical student anxiety.

Methods
\end{abstract}

A six-question pre-survey was administered to students to evaluate anxiety levels. Following completion of this survey, a certified therapy dog was introduced before each exam. After 10 weeks of exposure to the therapy dog, a 12-question post-survey was administered to students.

\section{Results}

The pre-survey $(n=183)$ demonstrated that $79 \%$ of students rated their anxiety level prior to an exam as a 5 or higher out of 10 on a Likert scale. However, after interacting with the therapy dog, the post-survey $(n=150)$ demonstrated that only $35 \%$ of students rated their anxiety as a 5 or higher. Additionally, $93 \%$ of students that inter-

*Corresponding author: Sara Brisson, Graduate Institute of Professional Psychology, University of Hartford, West Hartford, Connecticut, USA, Tel: +1 5712189706; E-mail: brisson@hartford.edu

Citation: Brisson S, Purkey S, Brisson M (2017) Medical Students' Attitudes Regarding the Impact of a Therapy Dog Program on Anxiety Levels: A Pilot Study. J Psychiatry Depress Anxiety 3: 010.

Received: November 03, 2017; Accepted: December 11, 2017; Published: December 25, 2017 acted with the therapy dog reported that the dog had an impact on their anxiety level and improved their learning and testing environment. Overall, $96 \%$ of students recommended the implementation of a permanent therapy dog program.

\section{Conclusion}

This study is the first to assess the impact of a therapy dog on anxiety levels of medical students. The students were near unanimous regarding a positive impact on their level of anxiety and continuation of a permanent therapy dog program.

Keywords: Anxiety; Medical Students; Therapy Dog

\section{Introduction}

The therapeutic value of human-animal interactions, which includes Animal-Assisted Therapy (AAT), Animal-Assisted Activities (AAA), and general animal interactions, have been widely recognized and accepted among the public due to reported physiological, psychological, and social benefits [1-4]. Benefits include a decrease in blood pressure and pulse [5,6]; a decrease in stress, anxiety, depression, and other mood disorders $[3,5,7]$; as well as improved social interactions and relations $[1,3]$. Individuals diagnosed with a severe mental illness have also reported that their pets were their primary and most valued social support in their life. They reported that their pets help them manage their feelings, distract them from their symptoms, and provide them with encouragement for daily activity $[8,9]$.

Over the past several years, AAT has become more prevalent on undergraduate and graduate campuses, particularly during exam periods $[10,11]$. Some educational institutions that have successfully implemented permanent therapy dog programs include, Yale Law School, University of Connecticut, Fordham University, Rochester Institute of Technology, and Tufts University [12].

However, there is still a lack of AAT on medical school campuses, where anxiety, depression, and suicidal ideations are prevalent among medical students [13-16]. Research has demonstrated a relationship between chronic anxiety and depression in predisposed individuals. Specifically, sustained stress and anxiety leads to elevated Cortisol and reduced serotonin and other neurotransmitters in the brain, such as dopamine, which have been linked to depression. When the stress response fails to shut off, such as while attending medical school, it can lead to depression in susceptible individuals $[17,18]$.

A survey study of 482 medical students found a high prevalence of anxiety and depression. Overall, $44 \%$ of students reported symptoms of anxiety and depression with $46 \%$ from first year students, $53 \%$ from second year, $47 \%$ from third year, and $29 \%$ from fourth year [17]. Another study that utilized a systematic review and meta-analysis of 195 studies, which included over 125,000 medical students from 47 different countries found that $27 \%$ of medical students screened positive for depression and that $11 \%$ reported suicidal ideation while attending medical school. Furthermore, only $16 \%$ of students who screened positive for depression reported that they sought treatment during their schooling. These findings are concerning given that the development of depression and suicidality has been linked to an increased short-term risk of suicide as well as a higher long-term risk of future depressive episodes and morbidity [15]. 
Few studies have been conducted to evaluate the impact of alternative therapeutic interventions on the anxiety level of medical students [19-21]. No research has examined the impact and effectiveness of a therapy dog program on the anxiety level of medical students. The purpose of this study is to evaluate the impact of a therapy dog on self-reported anxiety levels of first and second-year medical students. We hypothesized that among the students who interacted with the therapy dog, the interaction would decrease levels of self-reported anxiety before and after their exam.

\section{Methods}

Following IRB exemption, 76 first-year and 107 second-year medical students $(n=183)$ completed an anonymous, online survey to evaluate their various levels of anxiety throughout medical school. The pre-survey contained six questions that evaluated general student anxiety while in school, anxiety prior to an exam, and anxiety immediately following the completion of an exam (Appendix 1). The following week, after completion of the pre-surveys, a certified therapy dog was introduced to the students in the morning for one hour before an exam. The therapy dog was located outside the entrance of the school so that students had the option to either engage or not engage with the therapy dog. However, every student entering the building at least could view the therapy dog and other students interacting with him. The therapy dog was available for 10 weeks prior to each first and second-year exam, which averaged about three mornings each week. After the 10-week program, an anonymous, online 12 question post-survey was administered to students, which 67 first-year and 83 second-year students $(n=150)$ completed. It contained 12 questions that evaluated general level of anxiety while in school, level of anxiety prior to an exam, and level of anxiety immediately following an exam (Appendix 2). The survey also included whether students interacted with the therapy dog and, if so, how many times they interacted, what their interactions were like, and their level of anxiety prior to an exam after interacting with the therapy dog. For students that engaged with the therapy dog, we defined interactions as petting, playing, or observing the therapy dog. As a final section of our survey, we asked their opinion on the impact of the therapy dog program on their learning and testing environment, whether they supported the continuation or expansion of the program at their school, and whether they were in favor of the implementation of therapy dog programs at other medical schools.

\section{Results}

As reported on the pre-survey, which 183 medical students completed, $79 \%$ of students $(n=145)$ rated their anxiety prior to an exam as a 5 or higher on the 10-point Likert scale. Higher scores represented higher levels of anxiety. These results are illustrated in figure 1. Following the implementation of a therapy dog on campus and administration of the post-survey, which 150 medical students completed, only $35 \%$ of students ( $n=53$ ), after interacting with the therapy dog, reported their anxiety at a level of 5 or higher. Higher scores represented higher levels of anxiety. These results are illustrated in figure 2. Additionally, 93\% of students $(n=140)$ that completed the post-survey responded that the interaction with the therapy dog had a noticeable impact on their anxiety prior to the exam and that the therapy dog improved their learning and testing environment. Furthermore, results demonstrated that $96 \%$ of students $(n=144)$ favored the placement of a permanent therapy dog at their school and at medical school campuses in general. These results highlight that even though
$3 \%$ of students $(n=5)$ did not experience a noticeable decrease in anxiety, they still view the therapy dog program as beneficial to the medical school community.

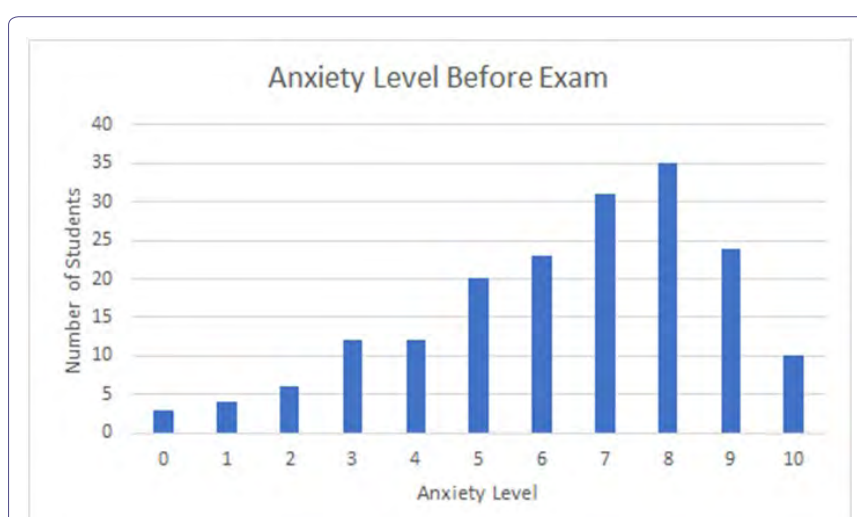

Figure 1: Pre-survey self-reported medical student anxiety prior to an exam.

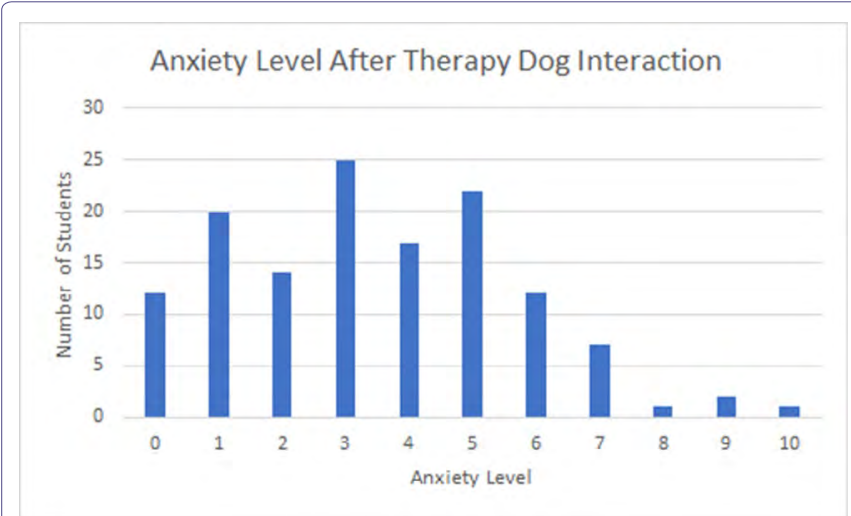

Figure 2: Post-survey self-reported student anxiety after interacting with the therapy dog prior to an exam.

\section{Discussion}

This study was designed to determine the impact that a therapy dog can have on self-reported anxiety. Mental health among medical students has become an increasing concern in the United States [1316], yet there is a lack of reliable interventions being implemented on medical school campuses [19-21]. After implementing a therapy dog program at an osteopathic medical school campus for 10 weeks, survey results demonstrated a potential decrease in self-reported student anxiety prior to taking an exam. These preliminary results suggest that the presence of and interaction with a therapy dog prior to an exam may aid in the decrease of anxiety among medical students.

However, there are limitations. We did not monitor participation from the pre-survey, which 183 students completed, to the post-survey, which only 150 students completed. Due to this, we are not able to appropriately conclude whether there was a significant decrease in anxiety among students potentially influenced by the therapy dog. We can only infer that there was a decrease. This allows for the expansion of this work in future studies to include a measure to evaluate student participation in the pre- and post-survey. Furthermore, while we are only inferring that the therapy dog influenced a decrease in student 
anxiety, it is important to consider other confounders that may have decreased anxiety, such as individual differences or maturation.

Overall, this pilot study is the first to evaluate the impact of a therapy dog program on self-reported anxiety levels of medical students prior to an exam. Results justify a more rigorous examination of the effectiveness of a therapy dog program on medical school campuses. Additionally, this study provides support for investigation into the impact of a therapy dog program on other aspect of medical student life, such as during class and clinical rotations. Our findings suggest that a therapy dog has the potential to decrease anxiety among students and accurately demonstrate that a therapy dog had a positive impact on the learning and testing environment. Continuation and expansion of the program is highly encouraged among students.

\section{Acknowledgement}

We have no acknowledgements to report.

\section{References}

1. Beetz A, Uvnäs-Moberg K, Julius H, Kotrschal K (2012) Psychosocia and psychophysiological effects of human-animal interactions: The possible role of oxytocin. Front Psychol 3: 234

2. Lutzky-Cohen N (2016) Motivation to use Animal-Assisted Therapy (AAT) among counselling and clinical psychology graduate students. University of Toronto, Ontario, Canada.

3. Rabbitt S, Kazdin A, Hong J (2014) Acceptability of animal-assisted therapy: attitudes toward AAT, psychotherapy, and medication for the treatment of child disruptive behavioral problems. Anthrozoos: A Multidisciplinary Journal of the Interactions of People \& Animals 27: 335-350.

4. Uvnäs-Moberg K, Arn I, Magnusson D (2005) The psychobiology of emotion: the role of the oxytocinergic system. Int J Behav Med 12: 59-65.

5. Allen K (2002) Cardiovascular reactivity and the presence of pets, friends, and spouses: The truth about cats and dogs. Psychosom Med 64: 727-739.

6. Odendaal JS, Meintjes RA (2003) Neurophysiological correlates of affiliative behaviour between humans and dogs. Vet J 165: 296-301.

7. Miller S, Kennedy C, Devoe D, Hickey M, Nelson T, et al. (2009) An examination of changes in oxytocin levels in men and women before and after interaction with a bonded dog. Anthrozoos: A Multidisciplinary Journal of the Interactions of People and Animals 22: 31-42.
8. Brooks H, Rushton K, Walker S, Lovell K, Rogers A (2016) Ontological security and connectivity provided by pets: A study in the self-management of the everyday lives of people diagnosed with a long-term mental health condition. BMC Psychiatry 16: 409.

9. Ross E (2016) Pets help people manage the pain of serious mental illness Health News from NPR.

10. Adamle KN, Riley TA, Carlson T (2009) Evaluating college student interest in pet therapy. J Am Coll Health 57: 545-548.

11. Reynolds JA, Rabschutz L (2011) Studying for exams just got more relaxing-Animal-assisted activities at the university of Connecticut library. College \& Undergraduate Libraries 18: 359-367.

12. Staff Writers (2017) 10 colleges with successful pet therapy programs.

13. Dyrbye LN, Thomas MR, Shanafelt TD (2006) Systematic review of depression, anxiety, and other indicators of psychological distress among US and Canadian medical students. Acad Med 81: 354-373.

14. Paro HB, Morales NM, Silva CH, Rezende CH, Pinto RM, et al. (2010) Health-related quality of life of medical students. Med Educ 44: 227-235.

15. Rotenstein LS, Ramos MA, Torre M, Segal JB, Peluso MJ, et al. (2016) Prevalence of depression, depressive symptoms, and suicidal ideation among medical students: a systematic review and meta-analysis. JAMA 316: $2214-2236$

16. Schwenk TL, Davis L, Wimsatt LA (2010) Depression, stigma, and suicidal ideation in medical students. JAMA 304: 1181-1190.

17. Jadoon NA, Yaqoob R, Raza A, Shehzad MA, Zeshan SC (2010) Anxiety and depression among medical students: a cross-sectional study. J Pak Med Assoc 60: 699-702.

18. Nepon J, Belik SL, Bolton J, Sareen J (2010) The relationship between anxiety disorders and suicide attempts: Findings from the National Epidemiologic Survey on Alcohol and Related Conditions. Depress Anxiety 27: 791-798.

19. Al-Dubai SAR, Al-Naggar RA, Al-Shagga MA, Rampal KG (2011) Stress and coping strategies of students in a medical faculty in Malaysia. Malays J Med Sci 18: 57-64.

20. Howe A, Smajdor A, Stöckl A (2012) Towards an understanding of resilience and its relevance to medical training. Med Educ 46: 349-356.

21. Warnecke E, Quinn S, Ogden K, Towle N, Nelson MR (2011) A randomized controlled trial of the effects of mindfulness practice on medical student stress levels. Med Educ 45: 381-388. 
Citation: Brisson S, Purkey S, Brisson M (2017) Medical Students' Attitudes Regarding the Impact of a Therapy Dog Program on Anxiety Levels: A Pilot Study. J Psychiatry Depress Anxiety 3: 010.

\section{Appendix 1}

Pre-Survey Questionnaire

\begin{tabular}{|c|c|c|c|c|c|c|c|c|c|c|c|c|}
\hline 1 & Gender & \multicolumn{11}{|c|}{$\begin{array}{c}\text { Male } \\
\text { Female }\end{array}$} \\
\hline 2 & Age & \multicolumn{11}{|c|}{$\begin{array}{c}<21 \\
21-25 \\
26-30 \\
31-40 \\
36-40 \\
>40\end{array}$} \\
\hline 3 & Rate your anxiety level on a non-exam day & 0 & 1 & 2 & 3 & 4 & 5 & 6 & 7 & 8 & 9 & 10 \\
\hline 4 & Rate your anxiety level on an exam day & 0 & 1 & 2 & 3 & 4 & 5 & 6 & 7 & 8 & 9 & 10 \\
\hline 5 & Rate your anxiety level immediately following an exam & 0 & 1 & 2 & 3 & 4 & 5 & 6 & 7 & 8 & 9 & 10 \\
\hline
\end{tabular}

\section{Appendix 2}

Post-Survey Questionnaire

\begin{tabular}{|c|c|c|c|c|c|c|c|c|c|c|c|c|}
\hline 1 & Gender & \multicolumn{11}{|c|}{$\begin{array}{l}\text { Male } \\
\text { Female }\end{array}$} \\
\hline 2 & Age & \multicolumn{11}{|c|}{$\begin{array}{c}<21 \\
21-25 \\
26-30 \\
31-40 \\
36-40 \\
>40\end{array}$} \\
\hline 3 & Rate your anxiety level on a non-exam day & 0 & 1 & 2 & 3 & 4 & 5 & 6 & 7 & 8 & 9 & 10 \\
\hline 4 & Rate your anxiety level on an exam day & 0 & 1 & 2 & 3 & 4 & 5 & 6 & 7 & 8 & 9 & 10 \\
\hline 5 & Rate your anxiety level immediately following an exam & 0 & 1 & 2 & 3 & 4 & 5 & 6 & 7 & 8 & 9 & 10 \\
\hline 6 & Did you have an interaction with Hodges, the therapy dog? & \multicolumn{11}{|c|}{$\begin{array}{l}\text { Yes } \\
\text { No }\end{array}$} \\
\hline 7 & How many days did you interact with the therapy dog before an exam? & \multicolumn{11}{|c|}{$\begin{array}{c}1 \text { to } 6 \text { time(s) } \\
7 \text { to } 12 \text { times } \\
\text { More than } 13 \text { times }\end{array}$} \\
\hline 8 & Please describe your interaction with the therapy dog & \multicolumn{11}{|c|}{$\begin{array}{c}\text { Played with Pet } \\
\text { Walked by and observed }\end{array}$} \\
\hline 9 & Rank your anxiety level after interacting with the therapy dog on an exam day & 0 & 1 & 2 & 3 & 4 & 5 & 6 & 7 & 8 & 9 & 10 \\
\hline 10 & $\begin{array}{c}\text { Overall, did the presence of the therapy dog have an impact on your anxiety level and } \\
\text { improve your learning/testing environment? }\end{array}$ & \multicolumn{11}{|c|}{$\begin{array}{l}\text { Yes } \\
\text { No }\end{array}$} \\
\hline 11 & Would you recommend a permanent therapy dog program for medical school campuses? & \multicolumn{11}{|c|}{$\begin{array}{l}\text { Yes } \\
\text { No }\end{array}$} \\
\hline
\end{tabular}

